\section{Sunset for dangerous chemicals}

SIR-Work on existing chemicals that are dangerous to man and/or the environment tends to focus on one issue at a time, at present chlorofluorocarbons (CFCs). For many years, polychlorinated biphenyls have been given the same intense attention. Plans to phase out these chemicals are under way. But such plans take a long time to develop, are very resourcedemanding and may lead to development of alternatives that pose other threats.

In my view, however, the number of chemicals that need to be phased out is too large to allow time to proceed case by case. My suggestion is that we try to establish a process, nationally or, preferably within some international organization, such as the Organisation for Economic Development (OECD), whereby chemicals that need to be phased out (sunset chemicals), are identified according to generally accepted criteria.

The procedure might be as follows. (1) Identify, according to set criteria, a number of chemicals (say 50 or 100) that should be phased out.

As a basis, lists of 'priority' chemicals, or of chemicals with specific hazardous properties - carcinogenic, mutagenic, teratogenic or hazardous to the environment - could be used. Criteria should be established whereby 'multiproblem' chemicals are distinguished. Step 1 would involve setting-up expert committees to develop criteria and the chemicals to be selected.

(2) Advertise the list, giving a proposed date for the phasing out of each chemical. At this stage, industry must be allowed to argue why a certain chemical should not be phased out. In Sweden this means that industry has to prove beyond reasonable doubt that the chemical in question is not a candidate for a sunset list.

(3) Once the list has been agreed to, nationally and/or internationally, companies could be obliged to report annually on the development of the phase-out. There should be a rule that no company must report a figure similar to or higher than that of the year before.

It is important to stress the quantitative aspect of the process because these are chemicals we want to get rid of. Companies may of course also report on protective measures, but this must not confuse the goal. The Swedish experience, for example with the Halving of Pesticides Programme, shows that such quantitative goals promote incentive and ingenuity.

(4) Results should be published regularly. On a national level, companies could compete, for example, for the title 'Company of the year'.

(5) The process should end with a ban, the sunset. Such a ban should be inherent in the process from the start. Responsible companies will have developed alternatives or closed processes, while less responsible companies will be punished for not having done so. Discussions and agreements between governments and industry will be a normal part of the process.

Such a process may be started at a national level and implemented by national legislation and regulation. As most chemicals move extensively in international trade and thus appear in, for example, many OECD member countries, the process needs to be internationalized. And a common understanding of the process within the international community would be an important step towards greater co-operation and harmonization between countries. The OECD could set an example to the rest of the world and take a strong lead on the road to a sustainable future.

\section{Swedish National Chemicals \\ Inspectorate,}

\section{Box 1384 ,}

S-171 27 Solna, Sweden

\section{Academic boycotts}

SIR-Distinguishing academic from sports boycotts of South Africa ("Academics, cricket and apartheid" Nature 340, 413; 1989) does seem appropriate in the light of the vital need for Great Britain and other nations steadfastly to support the academic institutions in South Africa that will be so essential in buttressing a post-apartheid society. In modern history, universities have generally outlasted the institutions of government, but that trend is likely to continue only if international support for a university's programmes is maintained in all but the most extraordinary circumstances, such as those now existing in China, where such support requires a degree of cooperation with the home government that is squarely inconsistent with the home government's actions against university welfare. Even in the case of China, international support should be eagerly reinstated as soon as conditions become acceptable, because, as with South Africa, the ability of the nation to make a transition toward a more open society depends, in part, on the vitality of the university. The university, much like the church, should be boycotted only when the institution itself cannot serve its universal mission under government stricture. A foreign government's displeasure can, in most situations, be conveyed by less injurious means.

College of Arts and Sciences,

Tulane University,

New Orleans, Louisiana 70118, USA WILLIAM E. COOPER

\section{Journal costs}

SIR-My mail this morning contained no fewer than half-a-dozen announcements of journals to which my poverty-stricken library was invited to subscribe. In every single case, the subscription costs quoted included both an 'individual rate', and an 'institutional rate' of anything up to twice as much. As medical staff in this country have received pay awards at least in line with official inflation figures, whereas my library budget has remained the same for the past three years, this seems unfair and ultimately self-defeating.

The problem lies in the fact that the production of new journals is, on the whole, supply-led rather than demandled. Scientists are not so eager to learn of new developments in their specialized sub-fields as to be willing to put their hands in their pockets and pay for the knowledge contained in new journals. Rather, it seems to be the case that scientists are well aware that appointment, tenure, promotion and grant-awarding go by the number of papers published, and so are keen to find new outlets to publish in. I have heard rumours of one who boasted of having managed to publish 16 papers based on the same set of data. Although this is, I hope, an extreme case, it is undoubtedly common to find that several parts of what is clearly the same study have been published, under different permutations of authors' names, in different journals, thus making it impossible for an individual with a personal subscription to one relevant journal to cover the study adequately.

The solution seems to me to be to find some other way of selecting candidates for appointment, tenure and so on. Surely the best and brightest minds of the scientific world, currently fully engaged in making sure that their names are somewhere in the list of authors of anything their graduate students publish, could find some better method of assessing each other? If the only scientific papers published were those needed to inform other scientists of new developments, a considerable proportion of these new journals would die of inanition.

If your own publication, $\mathrm{Sir}$, was genuinely devoted to maximizing the distribution of scientific information, I am sure that you would admit that handling institutional subscriptions is less work for you than handling individual subscriptions, and would be offering institutional subscriptions at half the price of those of individuals, rather than the other way round.

Institute of Psychiatry,

MARTIN GUHA

De Crespigny Park, Denmark Hill,

London SE5 8AF, UK

See also p.349. 